\title{
ВMJ Global Health Initial success from a public health approach to hepatitis $C$ testing, treatment and cure in seven countries: the road to elimination
}

Caroline E Boeke (D) , ${ }^{1}$ Clement Adesigbin, ${ }^{2}$ Chukwuemeka Agwuocha, ${ }^{3}$ Atiek Anartati, ${ }^{4}$ Hlaing Thazin Aung, ${ }^{5}$ Khin Sanda Aung, ${ }^{6}$ Gagandeep Singh Grover, ${ }^{7}$ Dang Ngo, ${ }^{8}$ Emi Okamoto, ${ }^{9}$ Alida Ngwije, ${ }^{10}$ Sabin Nsanzimana, ${ }^{11}$ Siddharth Sindhwani, ${ }^{12}$ Grace Singh, ${ }^{1}$ Ly Penh Sun, ${ }^{13}$ Nguyen Van Kinh, ${ }^{14}$ Wiendra Waworuntu, ${ }^{15}$ Craig McClure ${ }^{1}$

To cite: Boeke CE, Adesigbin C, Agwuocha C, et al. Initial success from a public health approach to hepatitis $\mathrm{C}$ testing, treatment and cure in seven countries: the road to elimination. BMJ Global Health 2020;5:e003767. doi:10.1136/ bmjgh-2020-003767

Handling editor Senjuti Saha

Received 24 August 2020 Revised 20 0ctober 2020 Accepted 11 November 2020

\section{Check for updates}

(c) Author(s) (or their employer(s)) 2020. Re-use permitted under CC BY-NC. No commercial re-use. See rights and permissions. Published by BMJ.

For numbered affiliations see end of article.

\section{Correspondence to} Dr Caroline E Boeke; caroline.boeke@mail.harvard. edu

\section{ABSTRACT}

With political will, modest financial investment and effective technical assistance, public sector hepatitis C virus (HCV) programmes can be established in low- and middle-income countries as a first step towards elimination. Seven countries, with support from the Clinton Health Access Initiative (CHAl) and partners, have expanded access to HCV treatment by combining programme simplification with market shaping to reduce commodity prices. CHAl has supported a multipronged approach to HCV programme launch in Cambodia, India, Indonesia, Myanmar, Nigeria, Rwanda and Vietnam including pricing negotiations with suppliers, policy development, fast-track registrations of qualityassured generics, financing advocacy and strengthened service delivery. Governments are leading programme implementation, leveraging HIV programme infrastructure/ financing and focusing on higher-HCV prevalence populations like people living with HIV, people who inject drugs and prisoners. This manuscript aims to describe programme structure and strategies, highlight current commodity costs and outline testing and treatment volumes across these countries. Across countries, commodity costs have fallen from >US\$100 per diagnostic test and US\$750-US\$900 per 12-week pan-genotypic direct-acting antiviral regimen to as low as US\$80 per-cure commodity package, including WHO-prequalified generic drugs (sofosbuvir + daclatasvir). As of December 2019, 5900+ healthcare workers were trained, 2209209 patients were screened, and 120522 patients initiated treatment. The cure (SVR12) rate was $>90 \%$, including at lower-tier facilities. Programmes are successfully implementing simplified, decentralised public health approaches. Combined with political will and affordable pricing, these efforts can translate into commitments to achieve global targets. However, to achieve elimination, additional investment in scale-up is required.

\section{INTRODUCTION}

Approximately 71 million people globally are living with hepatitis $\mathrm{C}$ virus (HCV), ${ }^{1}$ a disease that can be diagnosed through screening and

\section{Summary box}

Hepatitis C can be diagnosed accurately through low-cost screening and confirmatory tests and cured in most patients with a well-tolerated 12-week oral regimen that works across virus genotypes. However, the cost of hepatitis $\mathrm{C}$ drugs has historically been prohibitively high in low- and middle-income countries.

- A multipronged approach, including decentralisation and reducing commodity prices, has been used to support hepatitis $\mathrm{C}$ programme launch in Cambodia India, Indonesia, Myanmar, Nigeria, Rwanda and Vietnam, leading the cost of drugs and diagnostics to drop to as low as US\$80 per patient. More than 5900 healthcare workers were trained on hepatitis $C$ care, over 2 million patients screened and over 120 000 initiated treatment; cure rates have been above $90 \%$.

- The experience of these countries suggests that with political will and affordable pricing, decentralised hepatitis $\mathrm{C}$ programmes are achievable in resourcelimited settings, paving the way for hepatitis $\mathrm{C}$ virus elimination.

confirmatory tests and cured in most patients with well-tolerated 12-week oral direct-acting antiviral (DAA) regimens effective across HCV genotypes. ${ }^{2}$ While DAA prices were previously a barrier in low- and middle-income countries (LMIC), recent price reductions have increased access. Concurrently, multiple diagnostic products and DAAs have received World Health Organization (WHO) prequalification. Given advances in availability and accessibility of drugs and diagnostics, the WHO endorsed global elimination of HCV by $2030 .^{3}$ 
To achieve elimination targets, the Clinton Health Access Initiative (CHAI), with support from the UK Foreign, Commonwealth and Development Office and in partnership with Duke Health, has worked since 2015 with governments and partners in Cambodia, India, Indonesia, Myanmar, Nigeria, Rwanda and Vietnam to operationalise a public health approach to HCV testing and treatment. CHAI is a technical assistance partner that operates hand-in-hand with governments to provide guidance on programme implementation. Leveraging context-specific strategies, all countries have rapidly expanded access to HCV cure by combining marketshaping to reduce prices with simplification of patient pathways.

The WHO-recommended simplified screening and treatment algorithm uses rapid diagnostic tests (RDT), viral load (VL) tests and DAAs. ${ }^{2}$ In 2019, a Call to Action was issued by regional liver societies to advocate for a decentralised, integrated approach to HCV testing and treatment in LMIC to achieve elimination, which emphasises simplification and task-sharing of uncomplicated HCV cases with non-specialists. ${ }^{4}$ However, more realworld evidence on the success of a decentralised approach to HCV care is needed from public sector programmes.

This manuscript describes implementation models used to provide HCV services in seven CHAI-supported LMIC and shares public sector data in order to highlight successes and achievements as well as challenges and lessons. We describe programme scale-up, testing and treatment volumes, diagnostic and drug price reductions, and treatment outcomes, in order to demonstrate that a decentralised public health approach has been possible in these settings and has led to positive outcomes.

\section{OVERVIEW OF APPROACH AND PROGRESS TO DATE}

While programme models and structures differ across countries, the approach to build a public sector programme has been similar. Key priorities included:

1. Pricing negotiations with diagnostic/drug suppliers.

2. Simplification of national diagnostic and treatment algorithms and guidelines, integration, decentralisation and task-shifting to general and nurse practitioners.

3. Fast-track registrations of quality-assured products.

4. Financing advocacy and partnerships.

5. Strengthened service delivery and monitoring and evaluation (M\&E).

A summary of the structure of the initial HCV testing and treatment programme in each country is provided in table 1, with highlights below. Most countries follow the 2018 WHO HCV Guidelines. ${ }^{2}$ Some countries initiated activities prior to receiving support from CHAI, which started in 2015. Several programmes started with a focus on HIV/HCV coinfected patients, who are at greater risk for advanced liver disease and liver-related mortality, ${ }^{5}$ leveraging HIV funding and infrastructure. Many programmes have also focused efforts on people who inject drugs (PWID), as unsafe injection is a key driver of HCV transmission in most settings. ${ }^{7}$

\section{Cambodia}

In Cambodia, estimated chronic HCV prevalence in the general population is $1.6 \%{ }^{1}$ Underspend in Global Fund HIV funding in 2017 was reprogrammed to screen approximately $68 \%$ of the national adult cohort on ART for HCV and subsequently diagnose and treat cases. Results from the HIV/HCV coinfection programme have informed the development of a national strategic plan and clinical guidelines, supported by key partners including the WHO and Médecins Sans Frontières (MSF). In addition to these government-led activities, MSF has treated $16332 \mathrm{HCV}$ patients since 2016 and developed simplified care models. ${ }^{8}$

\section{India (Punjab)}

The anti-HCV antibody prevalence in India is estimated at $0.85 \%,{ }^{9}$ with a substantially higher prevalence $\left(3.6 \%{ }^{10}\right)$ in Punjab State. For this reason, building a strong public sector programme in Punjab (initiated in 2016) has been a focus. Leveraging Punjab's model, India launched a national hepatitis programme in 2018 to screen 5 million people and treat 300000 patients in 3 years. The national programme sets policy, informs state decision making and allocates funding with a state cofinancing requirement. Of note, the private sector plays a role in the provision of healthcare in India and HCV services are provided to some outside of the public sector. Key partners include the WHO, Foundation for Innovative New Diagnostics (FIND), MSF and the Institute of Liver and Biliary Sciences in Delhi. The development of a strong M\&E system for Punjab has been adopted by other states.

\section{Indonesia}

Indonesia has an estimated anti-HCV antibody prevalence of $1.0 \% .{ }^{11}$ Indonesia's HCV programme launched in seven demonstration provinces in 2017 and expanded to eight additional provinces in 2018-2019. In 2019, a programme launched to eliminate HCV in prisons in Jakarta, and hepatitis was announced as a national priority. The country is moving to a national targeted screening approach for high-risk sub-populations such as PLHIV, PWID and prisoners; the elimination programme in prisons will be expanded across the country. Key partners include the WHO, Hepatologist Association and Yayasan Koalisi Satu Hati.

\section{Myanmar}

Anti-HCV antibody prevalence in Myanmar is estimated at $2.65 \% .{ }^{12}$ In 2017 , the government launched a public programme with treatment available free-of-charge in eight states and regions. To supplement the limited treatment courses in the public sector and scale up access, the government piloted a public private partnership (PPP) in 2018. Through the PPP, patients diagnosed in both public and private sectors who are not eligible for care through the limited public programme, but are able to pay out 


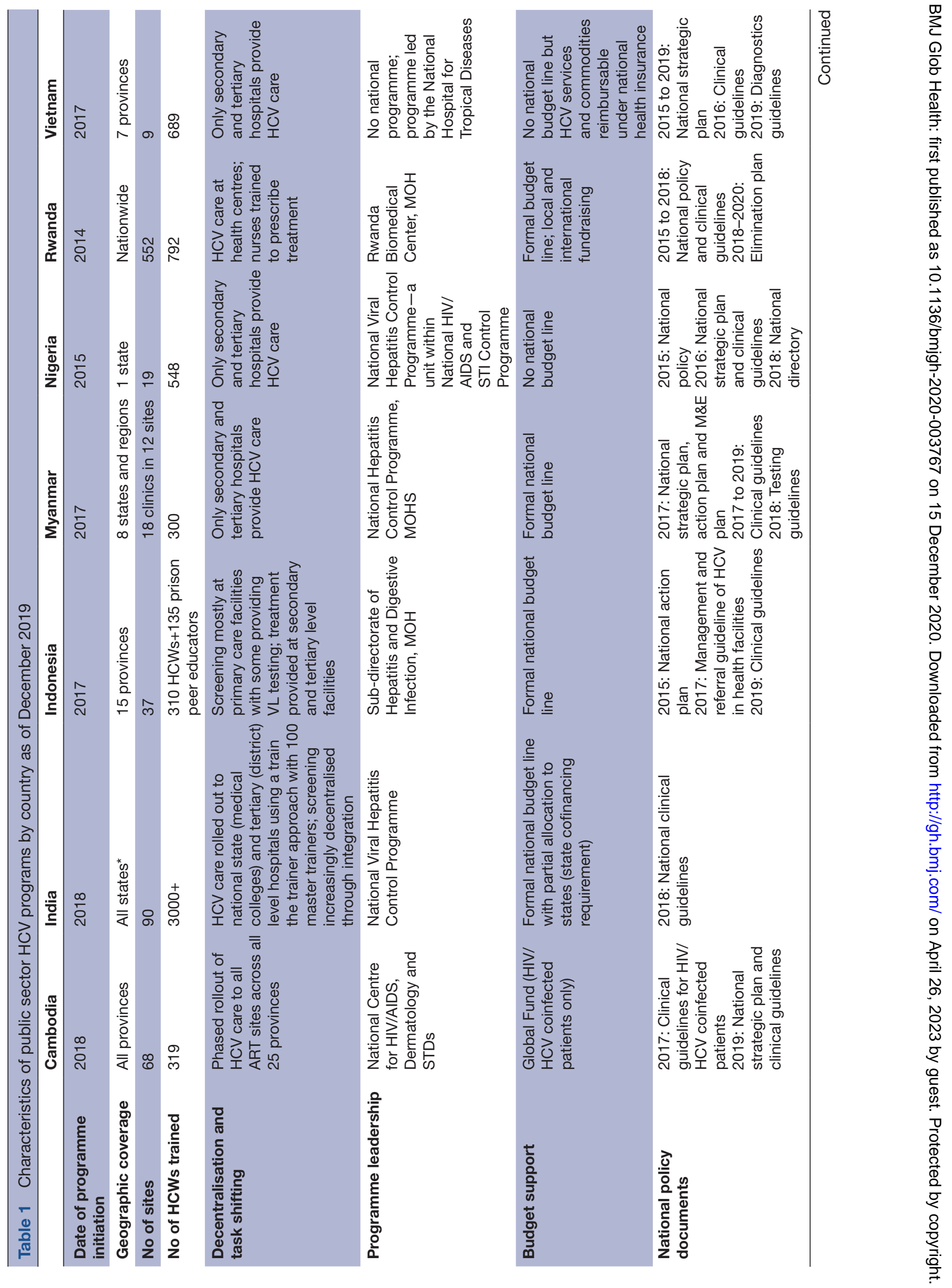




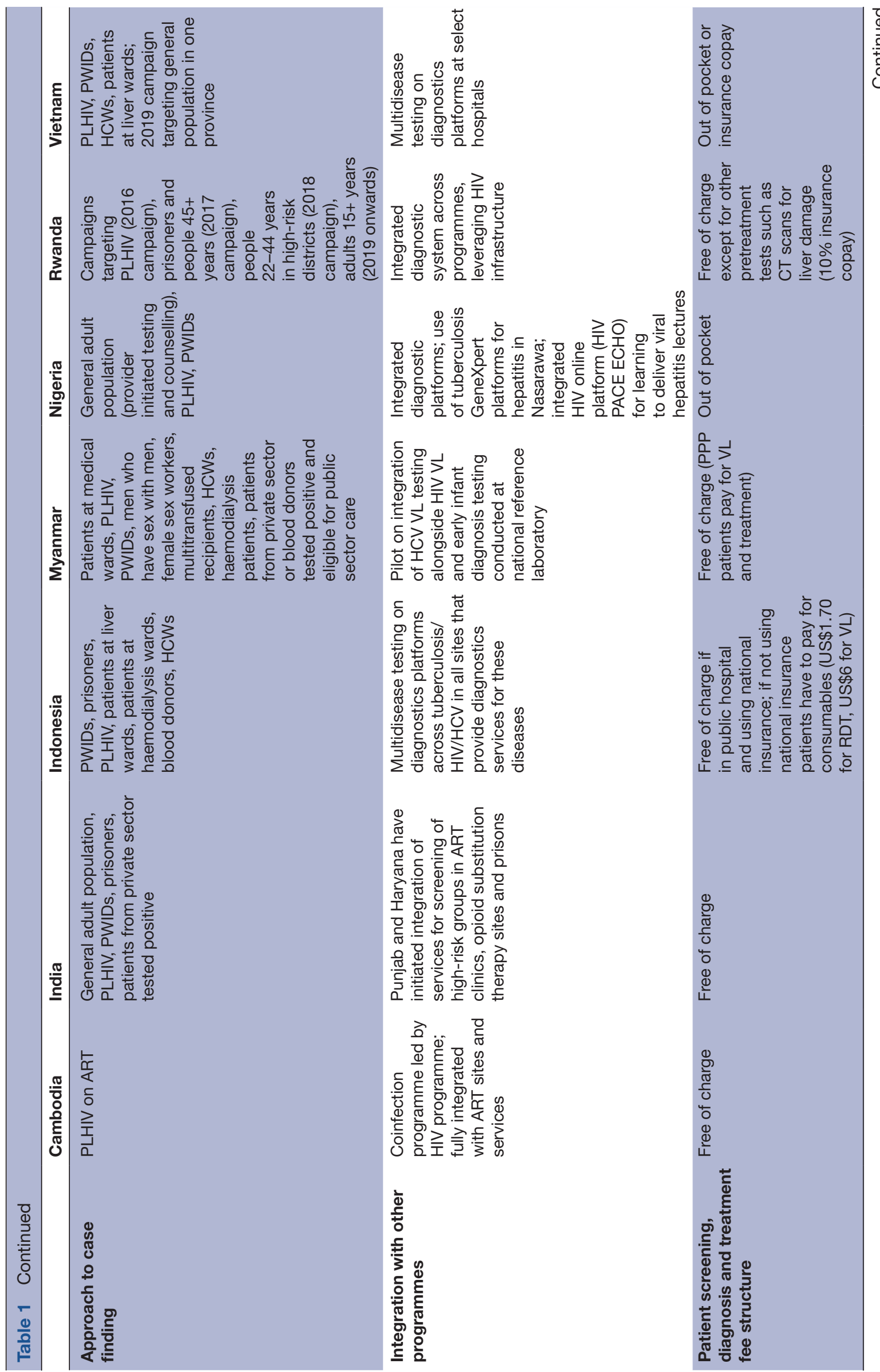


of pocket, have access to quality DAAs and diagnostics at reduced costs. Building on initial success, scale-up of the PPP is a primary strategy for Myanmar. Key partners include the WHO, FIND, MSF, Burnet Institute, Myanmar Liver Foundation, Medical Action Myanmar, Community Partners International and Myanmar Medical Association.

\section{Nigeria}

Nigeria has an estimated viraemic prevalence of $1.1 \% .^{13}$ CHAI supported initial programmes launched in 2015 in Nasarawa, a state with higher HCV prevalence $\left(13.2 \%^{14}\right)$ and Lagos, where the programme focused on providing care to PLHIV. Nasarawa state has allocated initial funding and launched a plan to eliminate HCV by 2024. A National Viral Hepatitis Control Programme is located within the National HIV/AIDS and Sexually Transmitted Infection (STI) Control Programme in the Federal Ministry of Health that supports policy-level work including guidelines development and national strategic planning, but no budget has been allocated to the programme yet. The primary partner is the WHO.

\section{Rwanda}

In Rwanda, the prevalence of anti-HCV antibodies is estimated at $4.0 \% .{ }^{15}$ Rwanda's HCV programme was initiated in 2014 with a targeted approach including short-term screening campaigns in high-risk populations, beginning with the HIV ART cohort, which was supported through reprogramming unspent Global Fund resources. The national programme has grown and decentralised over time; key accomplishments include task shifting HCV care to general practitioners. In 2018, the government committed to national elimination by 2023 . The target date for elimination was recently accelerated to 2021. Key partners include the Global Fund, the WHO, Partners in Health and MTEK Sciences.

\section{Vietnam}

The prevalence of anti-HCV antibody in Vietnam is estimated to be $1.0 \%-3.3 \% .{ }^{16}$ In 2017 , Vietnam initiated a small-scale public sector HCV programme in select provinces to generate evidence for scale-up of services. Building on the programme's strong results, the government updated its national health scheme in November 2018 to include coverage of four DAAs at a reimbursement rate of 50\%. Key partners include the WHO, ANRS, Medicins Du Monde, Supporting Community Development Initiatives and Vietnam Network of People who Use Drugs.

\section{Data aggregation and analysis}

Aggregate-level programme data were collated from government databases and records for this manuscript. The numbers encompass data from public sector programme initiation through December 2019. Data do not capture private sector activities. Statistics on training and numbers of facilities offering HCV treatment may have been defined differently across countries. 
Commodity pricing from distributors to governments was tracked by CHAI; public sector procurement pricing figures across quality-controlled diagnostic and drug products are presented.

Aggregate screening, VL testing, treatment and sustained virologic response (SVR12) volumes were calculated based on quarterly reporting across facilities in each country. Because the numbers were reported by quarter and in aggregate, there were some discrepancies between steps in the cascade of care. Despite data limitations, reported numbers across the cascade were included to provide broad information on the scale of HCV testing and treatment in each country and identify key points of lost to follow-up (LTFU) for future programme focus. The percentage of patients confirmed cured was calculated among those with SVR12 results available.

\section{Patient and public involvement}

Patients were not involved in this analysis.

\section{Commodity pricing reductions and access}

As of December 2019, $\geq 787$ facilities offered HCV screening and/or treatment services across the seven countries, and 5958+ healthcare workers were trained, with the largest programmes in Punjab, India and Rwanda (table 1). Since 2014, HCV treatment costs in LMIC have decreased dramatically from $>$ US $\$ 100$ per diagnostic test and US $\$ 750$-US $\$ 900$ per 12-week DAA for innovator products. As of December 2019, prices for diagnostics were as low as $<$ US\$1 per RDT and US\$8.90-US\$15 per VL test (depending on testing platform), and 12-week DAA regimens (typically sofosbuvir + daclatasvir) were as low as US\$39 in India (a locally manufactured, qualitycontrolled product, generic sofosbuvir + daclatasvir) and US\$60 in Rwanda (a WHO-prequalified product, generic sofosbuvir + daclatasvir), meaning that in some countries, the total commodity 'cost-per-cure' was as low as US $\$ 80$ (table 2). Note that this figure is based on the commodity pricing for a single individual and does not incorporate case-finding costs. ${ }^{17}$ DAA prices remain high (>US\$500) in some countries due to various price mark-ups. ${ }^{18}$
Decentralised care has been implemented to varying degrees across programmes. Primary health settings provide multiple services in Rwanda and screening in Indonesia, while other programmes provide care in secondary and tertiary settings. Successful integration of testing with other disease programmes and approaching case finding through high-risk subpopulations also have been demonstrated.

\section{Testing and treatment volumes achieved to date}

Testing and treatment volumes are shown in figure 1. Between programme initiation (2014-2017, country dependent) and December 2019, 2209209 people were screened for anti-HCV antibody, 194331 were reported to be antibody positive, 148590 received a VL test, 91 491 were confirmed viraemic (ie, had a detectable VL), 120522 were initiated on treatment, 54473 received an SVR12 test and 50811 achieved SVR12. The largest screening programme to date was in Rwanda, with 1.5 million patients screened as of December 2019, followed by Indonesia and Punjab, India. The largest volumes of anti-HCV antibody positive patients were observed in Punjab's programme (94 369), which also conducted the most VL tests (83 890), initiated the most patients (76 380 ) and confirmed the most cured patients (43 978) across the programmes.

Among viraemic patients with SVR12 data available $(\sim 55 \%)$, the percentage cured for those who initiated treatment was greater than $90 \%$ in each country, including in lower-tier facilities and HIV/HCV coinfection programmes.

\section{CHALLENGES AND OPPORTUNITIES}

Across these seven countries, HCV programmes facing different challenges have shown remarkable initial success. Simplification of diagnostic/treatment algorithms, integrating HCV care with other programmes, decentralisation and task shifting have proven possible in most settings and have helped boost screening and treatment rates. However, common challenges included

Table 2 Public sector product procurement pricing for quality-assured products from in-country distributors as of December $2019(\text { US } \$)^{\star}$

\begin{tabular}{llll}
\hline & Rapid diagnostic test & Viral load test & 12-week direct-acting antiviral regimen \\
\hline Cambodia & US $\$ 1$ & US $\$ 17$ & US $\$ 231$ \\
India (Punjab only)† & US $\$ 0.30$ & US $\$ 5.90$ & US $\$ 39$ \\
Indonesia & US $\$ 0.94$ & US $\$ 30.48$ & US $\$ 750$ \\
Myanmar & US $\$ 0.70$ & US $\$ 25$ & US $\$ 93$ \\
Nigeria & US $\$ 1.80$ & US $\$ 22$ & US $\$ 207$ \\
Rwanda & US $\$ 0.75$ & US $\$ 9.36$ & US $\$ 60$ \\
Vietnam $\ddagger$ & US $\$ 1.30$ & US $\$ 22.14$ & US $\$ 900$ \\
\hline
\end{tabular}

*The same commodities may be more expensive in the private sector.

†Prices are for locally manufactured products (not necessarily quality assured). Viral load test price derived using $50 \%$ of the bundled price for viral load test and SVR12 test. A 12-week direct-acting antiviral regimen cost is for a locally manufactured, quality-controlled product. $\ddagger$ Pricing reflects the lowest price that patients can access in a public sector facility. 
A

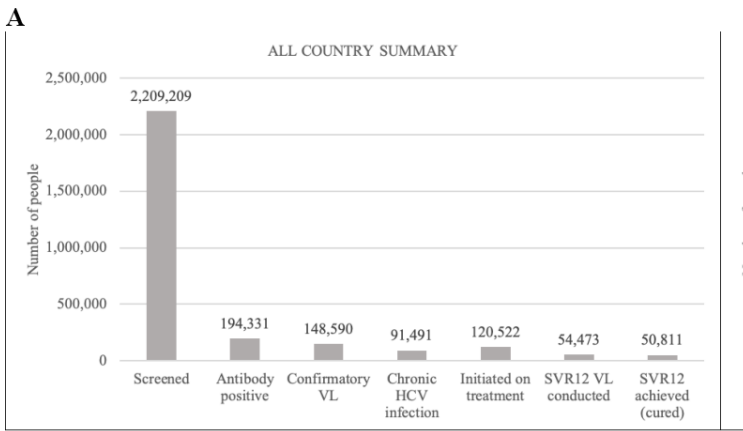

B

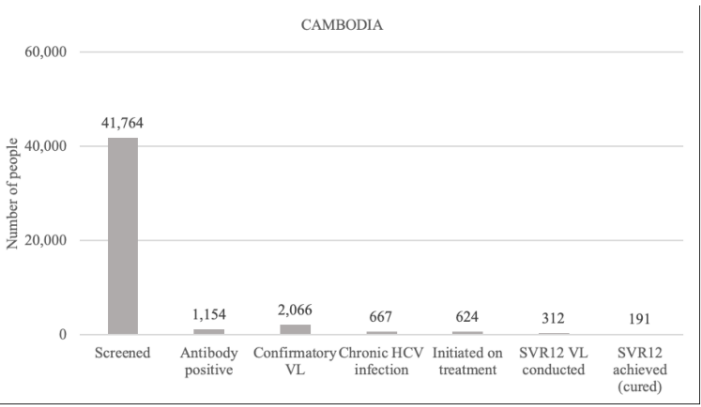

D
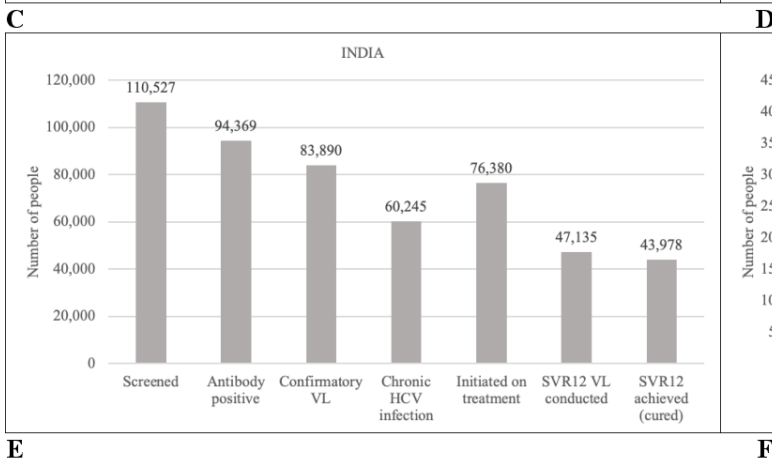

$\mathbf{F}$

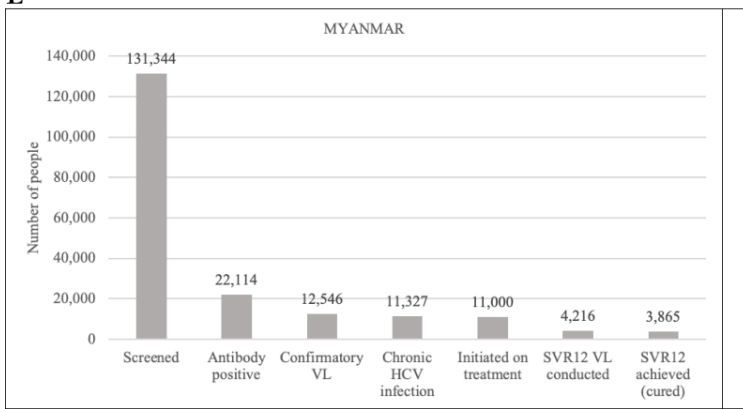

G

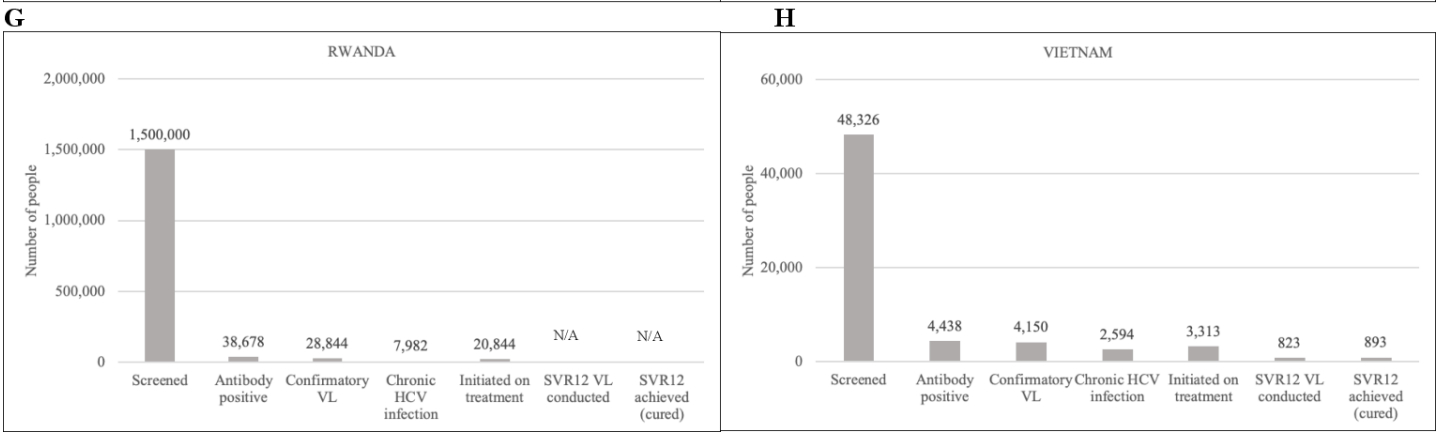

Figure 1 Aggregate cascade of care data between programme initiation (2014-2017, country dependent) and December 2019: all country summary (A) and numbers by country (B-H). ${ }^{1}$ Population size estimates from $2019^{29}$ and HCV prevalence estimates for each country are as follows: Cambodia: population: 16486542 prevalence: $1.6 \%{ }^{1}$; India: population: 1366 417 754; prevalence: $0.85 \%{ }^{9}$; Indonesia population: 270625 568: prevalence: $1.0 \%{ }^{11}$; Myanmar: population: 54045 420; prevalence: $2.65 \%{ }^{12}$; Nigeria: population: 200963 599; prevalence: $1.1 \%{ }^{13}$; Rwanda: population: 12626 950; prevalence: 4.0\% ${ }^{15}$; Vietnam: population: 96462 106; prevalence: $1.0 \%-3.3 \% .{ }^{16}$ Data in the figure from India are from the Punjab programme only. Data discrepancies across columns in some countries may be explained by the following factors: in Punjab, many facilities did not collect data on all patients screened, only the anti-HCV antibody positive patients. In several countries, only screening and treatment volumes were initially reported (not other indicators across the cascade of care), and therefore, the total number of patients reported as initiating treatment exceeded the number of patients with an elevated VL. In Cambodia, the number of confirmatory VL tests was higher than the number who screened positive because many individuals had already received RDTs previously through other mechanisms. Some programmes such as Rwanda did not historically distinguish between confirmatory VL testing and SVR12 testing, and therefore, did not have accurate SVR12 numbers. In Vietnam, numbers were combined across different data sources, leading the number of patients who were cured to look larger than the number of patients with an SVR12 test. Of note, in some countries, screening and viral load testing were conducted among people identified as high risk and subsequently tested, and therefore the proportion of tests that were positive does not equate to population prevalence of anti-HCV antibodies or viraemia. HCV, hepatitis C virus; RDT, rapid diagnostic tests; VL, viral load. 
limited case finding, high patient LTFU, weak data systems, high diagnostics and drug pricing and insufficient finances. In the following paragraphs, we discuss real-world examples to demonstrate ways to overcome these challenges.

In early stages of HCV infection, individuals are asymptomatic. ${ }^{19}$ To identify people living with HCV (PLHCV) for treatment, proactive approaches can be employed, such as focusing services on sub-populations at increased risk of HCV (eg, PLHIV ${ }^{20}$ prisoners,${ }^{21}$ PWID $^{7}$ ), running targeted screening and educational campaigns, or treating patients diagnosed in private sector care. In Cambodia and Rwanda, PLHCV were identified through established HIV programmes, leveraging existing programme infrastructure to screen, identify and treat coinfected PLHIV. Rwanda has demonstrated that this initial case finding and treatment approach can help build momentum towards a broader elimination programme. Screening campaigns, such as general population screening and education on World Hepatitis Day and/or campaigns to target specific high-risk populations are strategies to screen many people within a short time period and raise awareness. For example, Rwanda has conducted targeted screening campaigns among PLHIV, survivors of the 1994 genocide, prisoners and older adults that have many individuals to be linked to HCV care. However, for screening campaigns to be successful, systems must be in place to appropriately counsel patients who screen positive and link them to care. In Myanmar and India, the private sector has played an important role in case finding; in India, patients can be diagnosed in the private sector and then treated free of charge in the public sector programme.

Another challenge has been high LTFU at key points in the care cascade; across countries, the biggest gap appeared to be between treatment completion and SVR12 testing. While SVR12 testing is important for programme monitoring, data suggest that most patients who complete treatment should have achieved cure, and thus, the more concerning gaps in some country contexts were between confirmatory VL testing and treatment initiation and between treatment initiation and completion. Data from some countries point to gaps in the proportion of patients who screen anti-HCV antibody positive but do not then get a confirmatory VL test, such as in Nigeria, where VL testing is paid for out of pocket. LTFU may result from different factors including expensive services, long test processing times, logistical difficulties with referrals, patient stigma or burdens and poor communication/ follow-up from health facilities. ${ }^{22-26}$ In addition, HCV services often involve working with marginalised populations at higher risk of attrition. Special focus is needed to ensure that screening programmes are effective and that context-specific reasons for patient LTFU are identified and addressed.

Many countries have experienced challenges with data availability, quality and utilisation for decision making, highlighting a need to develop effective M\&E systems from the beginning. The strongest M\&E systems are digital, updated regularly, verified periodically for quality, accessible to decision-makers and integrated across disease areas. The HCV programme in Punjab designed a comprehensive web-based M\&E system for digitising relevant patient data that has been scaled up nationally. Other countries like Rwanda are prioritising M\&E system strengthening to support elimination. Still, some countries do not yet have electronic M\&E systems or have challenges with data completeness across sites. Continued focus on strengthening data systems is needed as programmes expand.

Lack of global donors has posed the biggest challenge for many countries. Most countries have limited domestic funding available, restricting the budget available for HCV services. The COVID-19 pandemic has strained budgets further and impacted HCV service delivery. In some countries, in-country mark-ups, limited in-country registrations, fragmented demand and low-volume orders keep commodity costs high. Strategies to achieve lower commodity pricing in countries include pooled procurement with substantial volume commitments, integrated testing across diseases, inclusive pricing models and using global pricing intel when setting up tendering processes. ${ }^{18}$ Countries will be most successful in obtaining better commodity pricing and achieving elimination targets if viral hepatitis services are coordinated by a national body with a dedicated budget to ensure coordinated procurement, enabling more generic supplier registrations and increasing market competition. However, in the absence of dedicated national hepatitis programmes and/or significant funding, countries have made substantial progress with targeted programmes in high-risk groups. Donor support for HCV elimination among PLHIV (eg, Cambodia, Rwanda) and other targeted approaches can catalyse broader viral hepatitis elimination efforts.

\section{CONCLUSION AND NEXT STEPS}

Programmes in sub-Saharan Africa and Asia have shown remarkable initial success in building decentralised public sector hepatitis $\mathrm{C}$ programmes with government leadership and support. Key next steps to improve services include: Continued work to achieve a healthy market for generic DAAs and prices for RDTs and RNA VL tests at/near parity with HIV pricing, with target pricing of a total commodity 'cost-per-cure' package of $\leq \mathrm{US} \$ 80$ in all countries; registering quality-assured generic drug manufacturers (currently 5 for sofosbuvir, 4 for daclatasvir) in-country; increased domestic and donor financing for HCV elimination; strengthened M\&E systems, including digital solutions to track patients across the cascade and manage commodity stock; integration with other programme areas, including HIV, harm reduction, sexual and reproductive health and primary care; further decentralisation and task-sharing of service delivery and expanded community engagement. 
In terms of next steps in these countries, Rwanda is the first to commit to national HCV elimination, with a formal government budget supplemented by local and international fundraising. India has committed to the scale-up of a national viral hepatitis programme, with a government budget supplemented with state-level cofinancing. Nasarawa State in Nigeria has committed to a 5-year target for HCV elimination. Cambodia has secured Global Fund financing to continue coinfection services and is hoping to launch a public HCV program in 2021. Indonesia is aiming to scale up the national programme to all 34 provinces by 2025 , with at least one hospital in each province providing HCV treatment. Myanmar will scale up treatment volumes by expanding and decentralising services in more states and regions, launching an HIV/HCV coinfection programme, and potentially expanding the PPP launched in 2018. Vietnam seeks to expand patient access by increasing the reimbursement rate of DAAs covered under health insurance and decentralising insurance coverage for HCV services to district facilities.

Most countries will need to update/develop HCV investment cases. The current cost and impact of achieving elimination has only been estimated in some settings, including Punjab (US\$350 million cost, saving an estimated 550000 lives and US\$188 million) $)^{27}$ and Indonesia (US $\$ 5.6$ billion cost or US $\$ 2.6$ billion with commodity price reductions, with an incremental costeffectiveness ratio of US $\$ 300$ per year of life saved). ${ }^{28}$ Given recent decreases in commodity pricing, updated costing will be important to better understand what will be needed to achieve elimination.

Despite relatively low volumes, a simplified public health approach positions the elimination of HCV in LMIC as a reasonable cost proposition with significant cost savings to be accrued over time given the comparatively high costs of managing complications of the disease if untreated. As a healthier market for commodities develops, pricing continues to fall and countries experience initial programme successes, the donor and domestic financing landscape will continue to evolve. However, advocacy at the global level is needed to continue building support for national HCV programmes in LMIC in order to achieve elimination.

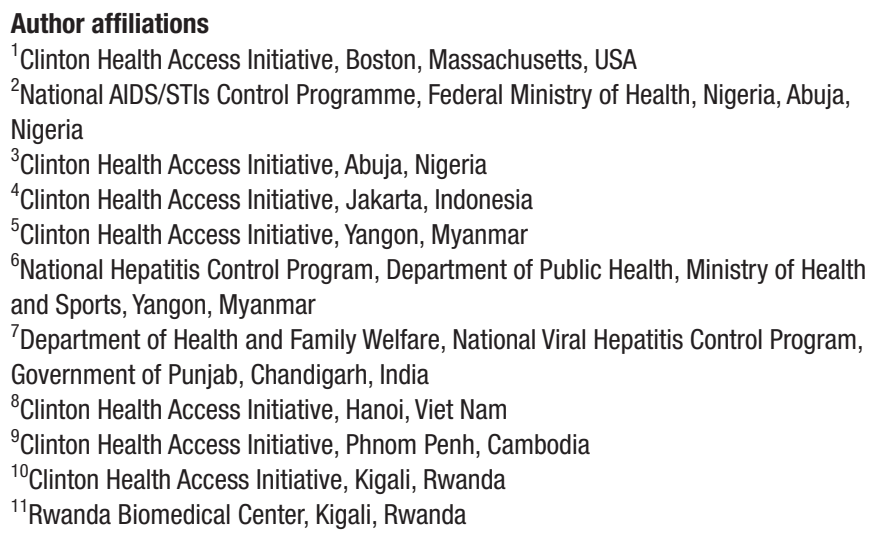

${ }^{11}$ Rwanda Biomedical Center, Kigali, Rwanda

${ }^{12}$ Clinton Health Access Initiative, Delhi, India

${ }^{13}$ National Center for HIV/AIDS, Dermatology, and Infectious Disease, Phnom Penh, Cambodia

${ }^{14}$ National Hospital of Tropical Diseases, Hanoi, Viet Nam

${ }^{15}$ Directorate of Communicable Disease Prevention and Control, Ministry of Health of the Republic of Indonesia, Jakarta, Indonesia

Twitter Clement Adesigbin @AdesigbinC

Acknowledgements We would like to acknowledge the government in each of these countries, CHAl programme staff, health facility staff and other key partners for their support of these programmes. Specifically, we would like to acknowledge Dr Khin San Tint, Ngeav Mao, Sovannarith Samrith, Sokphuong Phan, Sovathana Ky, Caroline Barrett, Ngauv Bora, Owens Wiwa, Folu Lufadejo, Justus Jiboye, Lilian Anomnachi, Olayinka Adisa, Akanmu Muhammed Mujtaba, Dr Ibrahim Adamu, Dr Ruth Adabe, Dr Musa Abdullahi, Dr Chukwuma Anyaike, Ena Oru, Ademola Osibesan, Dr Siti Nadia Tarmizi, Dr Regina T. Sidjabat, Dr Indri Oktaria Sukmaputri, Victoria Idrawati, Robert Kosasih, Arief Budiman, Niken Widyastuti, Ye Mon Kyaw, Thu Nguyen, Dr Cao Thuy, Oriel Fernandes, Sean Regan, Dr Christian Ramers, Magdalena Witschi, Yuhui Chan and Lara Grosso

Collaborators Dr. Khin San Tint; Ngeav Mao; Sovannarith Samrith; Sokphuong Phan; Sovathana Ky; Caroline Barrett; Ngauv Bora; Owens Wiwa; Folu Lufadejo; Justus Jiboye; Lilian Anomnachi; Olayinka Adisa; Akanmu Muhammed Mujtaba; Dr. Ibrahim Adamu; Dr. Ruth Adabe; Dr. Musa Abdullahi; Dr. Chukwuma Anyaike; Ena Oru; Ademola Osibesan; Dr. Siti Nadia Tarmizi; Dr. Regina T. Sidjabat; Dr. Indri Oktaria Sukmaputri; Victoria Idrawati; Robert Kosasih; Arief Budiman; Niken Widyastuti; Ye Mon Kyaw; Thu Nguyen; Dr. Cao Thuy; Oriel Fernandes; Sean Regan;Dr Christian Ramers; Magdalena Witschi; Yuhui Chan; Lara Grosso.

Contributors $C E B$ and $C M$ conceived of this manuscript and prepared the first draft. CAd, CAg, AA, HTA, KSA, GSG, DN, E0, AN, SN, SS, LPS, NVK and WW contributed to data collation and analysis. All authors contributed to data interpretation, critical review of the manuscript and approval of the manuscript in its final form.

Funding UK Foreign, Commonwealth and Development Office.

Competing interests None declared.

Patient and public involvement Patients and/or the public were not involved in the design, or conduct, or reporting, or dissemination plans of this research.

Patient consent for publication Not required.

Provenance and peer review Not commissioned; externally peer reviewed.

Data availability statement All data relevant to the study are included in the article.

Open access This is an open access article distributed in accordance with the Creative Commons Attribution Non Commercial (CC BY-NC 4.0) license, which permits others to distribute, remix, adapt, build upon this work non-commercially, and license their derivative works on different terms, provided the original work is properly cited, appropriate credit is given, any changes made indicated, and the use is non-commercial. See: http://creativecommons.org/licenses/by-nc/4.0/.

\section{ORCID iD}

Caroline E Boeke http://orcid.org/0000-0003-1939-1307

\section{REFERENCES}

1 Polaris Observatory HCV Collaborators. Global prevalence and genotype distribution of hepatitis $C$ virus infection in 2015: a modelling study. Lancet Gastroenterol Hepatol 2017;2:161-76.

2 World Health Organization. Guidelines for the care and treatment of persons diagnosed with chronic HCV infection. Geneva, Switzerland, 2018.

3 World Health Organization. Combating hepatitis $B$ and $C$ to reach elimination by 2030, 2016.

4 AASLD, EASL, APASL, ALEH. Call to action for liver associations to advance progress towards viral hepatitis elimination: a focus on simplified approaches to HCV testing and cure, 2019.

5 Weber R, Sabin CA, Friis-Møller N, et al. Liver-related deaths in persons infected with the human immunodeficiency virus: the D:A:D study. Arch Intern Med 2006;166:1632-41.

6 Deng L-P, Gui X-E, Zhang Y-X, et al. Impact of human immunodeficiency virus infection on the course of hepatitis $C$ virus infection: a meta-analysis. World J Gastroenterol 2009;15:996-1003. 
7 Zhou B, Cai GFF, Lv HKK, et al. Factors correlating to the development of hepatitis $C$ virus infection among drug UsersFindings from a systematic review and meta-analysis. Int $J$ Environ Res Public Health 2019;16:2345.

8 Zhang M, O'Keefe D, Iwamoto M, et al. High sustained viral response rate in patients with hepatitis $C$ using generic sofosbuvir and daclatasvir in Phnom Penh, Cambodia. J Viral Hepat 2020;27:886-95

9 Goel A, Seguy N, Aggarwal R. Burden of hepatitis C virus infection in India: a systematic review and meta-analysis. $J$ Gastroenterol Hepatol 2019;34:321-9.

10 Sood A, Suryaprasad A, Trickey A, et al. The burden of hepatitis C virus infection in Punjab, India: a population-based serosurvey. PLoS One 2018;13:e0200461.

11 Ministry of Health, Republic of Indonesia. National health survey, 2013.

12 Lwin AAA, Htun K.S.;, Kyaw M.M.;, et al. Sero-Prevalence of hepatitis $B$ and $C$ viral infections in Myanmar: national and regional survey in 2015. Myanmar Helath Science Research Journal 2017;29.

13 Nigeria National HIV/AIDS. Impact and indicator survey, 2018.

14 Pennap GRY, Oyige O, Forbi J. Prevalence of hepatitis B and C virus infection among people of a local community in Keffi, Nigeria. African Journal of Microbiology Research 2010;4:274-8.

15 Karoney MJ, Siika AM. Hepatitis C virus (HCV) infection in Africa: a review. Pan Afr Med J 2013;14:44.

16 World Health Organization, Western Pacific Region. Viral hepatitis situation and response in Viet Nam. Manila, Philippines, 2018.

17 Tordrup D, Hutin Y, Stenberg K, et al. Additional resource needs for viral hepatitis elimination through universal health coverage: projections in 67 low-income and middle-income countries, 201630. Lancet Glob Health 2019; 7:e1180-8.

18 Clinton Health Access Initiative (CHAl). Hepatitis $C$ market report, 2020.
19 Westbrook RH, Dusheiko G. Natural history of hepatitis C. $\int$ Hepatol 2014:61:S58-68.

20 Platt L, Easterbrook P, Gower E, et al. Prevalence and burden of $\mathrm{HCV}$ co-infection in people living with HIV: a global systematic review and meta-analysis. Lancet Infect Dis 2016;16:797-808.

21 Larney S, Kopinski H, Beckwith CG, et al. Incidence and prevalence of hepatitis $\mathrm{C}$ in prisons and other closed settings: results of a systematic review and meta-analysis. Hepatology 2013;58:1215-24.

22 Balkhy HH, El-Saed A, Sanai FM, et al. Magnitude and causes of loss to follow-up among patients with viral hepatitis at a tertiary care hospital in Saudi Arabia. J Infect Public Health 2017;10:379-87.

23 Lin M, Kramer J, White D, et al. Barriers to hepatitis C treatment in the era of direct-acting anti-viral agents. Aliment Pharmacol Ther 2017;46:992-1000.

$24 \mathrm{Li} \mathrm{T}$, Su S, Zhao Y, et al. Barriers to the prevention and control of hepatitis $B$ and hepatitis $C$ in the community of southwestern China: a qualitative research. Int J Environ Res Public Health 2019;16:231. doi:10.3390/ijerph16020231

25 Rich ZC, Chu C, Mao J, et al. Facilitators of HCV treatment adherence among people who inject drugs: a systematic qualitative review and implications for scale up of direct acting antivirals. $B M C$ Public Health 2016;16:994.

26 Treloar C, Rance J, Backmund M. Understanding barriers to hepatitis $C$ virus care and stigmatization from a social perspective. Clin Infect Dis 2013;57 Suppl 2:S51-5.

27 World Hepatitis Alliance and Clinton Health Access Initiative (CHAl). Developing an HCV investment case for Punjab (India), 2020.

28 Trickey A, Hiebert L, Perfect C, et al. Hepatitis C virus elimination in Indonesia: epidemiological, cost and cost-effectiveness modelling to advance advocacy and strategic planning. Liver Int 2020;40:286-97.

29 World Bank Group. Population estimates and projections, 2019. 